\title{
Examination of the Effectiveness and Acceptability of a Play-Based Sibling Intervention for Children with Autism: A Single-Case Research Design
}

\author{
Lindsay B. Glugatch (iD) Wendy Machalicek
}

Accepted: 30 May 2021 / Published online: 16 August 2021

(C) This is a U.S. government work and not under copyright protection in the U.S.; foreign copyright protection may apply 2021

\begin{abstract}
Complementary and reciprocal interactions are a defining feature of sibling relationships for young children. However, the social and communication difficulties of children with autism spectrum disorder (ASD) can make reciprocal play more difficult and play between siblings can be less rewarding. Sibling play can serve an important role in intervention and family cohesiveness, but there is no consistent method for involving siblings in intervention benefitting the sibling dyad. This study evaluated a novel treatment package including training siblings on play strategies to increase positive sibling play in combination with a sibling support group to offer social support for the neurotypical sibling (NT). The effects of the treatment package on NT sibling play and fidelity of implementation of naturalistic play strategies was examined using a concurrent multiplebaseline design across six dyads, five of whom completed the intervention. After behavior skills training, all NT siblings increased the number of strategies they used, and increased the frequency of initiations towards their sibling with ASD. In addition, the percentage of reciprocal play between siblings increased. Generalization probes and follow-up probes demonstrated abovebaseline levels of performance across most dyads, indicating that the skills learned generalized across other toys and were maintained over time. Only three of the sibling support group sessions were completed due to the COVID-19 pandemic. Although the effectiveness of
\end{abstract}

\section{B. Glugatch $(\bowtie) \cdot$ W. Machalicek}

Department of Special Education and Clinical Sciences,

University of Oregon, Eugene, OR 97403, USA

e-mail: lglugat2@uoregon.edu the sibling support group cannot be determined, social validity questionnaires suggest siblings and parents valued and liked the support group.

Keywords Autism · Sibling · Play · Support group · Intervention

The relationship between siblings, both during childhood and into adulthood, can play a pivotal role in a person's life. Growing up, siblings are readily available playmates, additional caregivers when the age span allows parents to entrust care to the older child (Kaminsky \& Dewey, 2001), and sources of peer-topeer inspiration (Baker, 2000). In adulthood, siblings can be close friends and confidants, share in the joys and tribulations of their own interpersonal relationships, and assist in the caring for their own children if they have them. As siblings grow older alongside one another, they share the many challenges that can come with life and offer a source of social emotional and sometimes financial support (Cicirelli, 1994; Laghi et al., 2018).

Although close friends or extended family members can similarly fill these roles, siblings uniquely offer an additional source of emotional support, opportunities to practice social and play skills with a peer within the family, and numerous occasions to practice resolving interpersonal conflicts. In fact, parents have often conveyed having siblings and a good relationship between them as essential to having a good childhood and family life (Gass et al., 2007). As with any relationship, the sibling relationship can be fraught with difficulty and 
frustrations (Bank \& Kahn, 1975; Kramer, 2004). Nevertheless, families of multiple children, including those families of children with neurodevelopmental disabilities, such as autism spectrum disorder (ASD), often have great expectations and hopes for the relationships between their children.

Complementary and reciprocal interactions are a defining feature of sibling relationships for young children (Bontinck et al., 2018). Furthermore, play is an instrumental part of relationship building in young children (Coelho et al., 2017), but the social and communication difficulties of children with ASD can make reciprocal play more difficult (Orsmond \& Fulford, 2018) and play between siblings can be less rewarding for children who have a sibling with ASD (Baker, 2000; McHale et al., 2016). The core social and communication difficulties encompassing an ASD diagnosis are unique when compared to other neurodevelopmental disabilities in that social support needs may affect relationships with siblings (Orsmond \& Fulford, 2018). In particular, young children with ASD are more likely to engage in repetitive and inflexible play behaviors compared to neurotypical children (Lin \& Koegel, 2018), display lower levels of functional and sociodramatic play (Jarrold, 2003), and requests for flexible play can often lead to challenging behaviors (Rispoli et al., 2014). However, one way of increasing appropriate sibling play is teaching NT siblings strategies to support their sibling with ASD (Kryzak \& Jones, 2017). For example, children with ASD showed improvements in joint engagement, turn-taking, and communication when the NT sibling incorporated the interests of the child with ASD into games (Baker, 2000), stayed in close proximity (Kryzak \& Jones, 2017), invited their sibling to play or share (Oppenheim-Leaf et al., 2012), and provided positive reinforcement (Colletti \& Harris, 1977). Sibling-mediated strategies are plausible intervention methods because siblings spend a considerable amount of time together across home and community settings; therefore, sibling-mediated interventions can potentially enhance skill generalization and maintenance of the skills for the child with ASD. Although studies have indicated that sibling-mediated interventions have produced positive outcomes for the child with ASD, most studies have failed to report outcomes for the sibling or the dyadic interaction (Banda, 2015). Of the studies that have reported sibling outcomes, the majority have only looked at sibling fidelity of implementation (Bene \& Lapina, 2020; Shivers \& Plavnick, 2015).
The broader research on siblings of children with ASD indicates there is some evidence of negative effects (e.g., poor mental health outcomes), but also evidence of positive effects (e.g., higher levels of social competence) suggesting siblings may simply need extra supports in place to support healthy development (Hastings, 2003; Tsao et al., 2012). Siblings of children with ASD may face unique challenges including feelings of embarrassment resulting from negative reactions from the public and may be best supported in learning how to navigate these ableist social encounters and in assisting their sibling with ASD during typical daily routines in the domains of adaptive skills, behavioral difficulties, and social impairments (Roeyers \& Mycke, 1995). Siblings of children with ASD compared to siblings of NT children or children with Down syndrome were at higher risk of poor outcomes such as social and behavioral difficulties (Giallo \& Gavidia-Payne, 2006), negative psychosocial outcomes, and higher rates of depression (Gold, 1993; Lovell \& Wetherell, 2016). On the other hand, other studies have reported siblings of children with ASD having high levels of social competence, positive self-concepts, and healthy behavioral adjustment (Ferraioli et al., 2012). Recent evidence suggests that when one sibling has ASD, the quality of relationship between siblings can be positive and, with the right supports, can positively affect personality characteristics of the NT sibling (Macks \& Reeve, 2007). Siblings of children with ASD may benefit from meeting other children with a similar family background and experiences. For instance, formal (e.g., doctor, counselor) and informal social supports (e.g., friends, family members) have been found to moderate the impact of severity of challenging behavior for the child with ASD and behavior outcomes for the NT sibling (Hastings, 2003).

Most researchers have focused on the impact of social support on parents and parent support groups, whereas some researchers have focused on sibling support groups (Lobato, 1985; Smith \& Perry, 2005; Summers et al., 1991). Like parent support groups, sibling support groups may be a successful method for siblings to connect with others and discuss their feelings in an emotionally safe space (Banach et al., 2010). Smith and Perry (2005) created the Treatment, Research, and Education for Autism and Developmental Disorders (TRE-ADD) program for siblings of children with ASD where siblings met for 8 consecutive weeks to increase their knowledge of autism, discuss feelings in an accepting space, share ways of coping through 
difficult situations, role play different strategies, enhance siblings' self-concepts, and encourage siblings to have fun. Siblings reported increased knowledge and understanding of ASD as well as more positive feelings about themselves. Other sibling support groups have combined recreational activities and discussionbased activities to encourage children to discuss feelings and enhance self-concepts (Christopher \& Shakila, 2013). At the end of the support group, siblings reported increased knowledge and self-concept. Kryzak et al. (2015) provided an extensive community intervention package that included a sibling support group, a skills intervention for the child with ASD, and recreation time. Themes of the support group included sharing information, how siblings made them feel, sharing good and bad feelings, learning about coping strategies, and increasing autism knowledge. The effects of the community program were mostly positive; NT siblings reported significant decreases in depression and anxiety and rated improvements in their peer network. However, their ASD knowledge did not significantly increase and there were no significant increases in reciprocal interactions between siblings. When specifically looking at the effect of sibling relationships using the Sibling Relationship Questionnaire (SRQ), findings were mixed; some studies reported higher scores suggesting more positive sibling relationships after the conclusion of the sibling support group, whereas other studies found no significant differences in relationships (Tudor \& Lerner, 2015). Thus, sibling support groups may provide siblings a way to connect and share experiences with others, but, these groups have not taught specific play and communication strategies for siblings to use with their siblings with ASD.

At present, there is a gap on the effects of a dual focused intervention package (i.e., training NT sibling in play strategies and a social support group) on NT sibling and play outcomes. The present study expands on the research on sibling-mediated interventions for children with ASD and includes a focus on NT sibling outcomes. NT children were taught to use simple play and behavior management strategies with their siblings with ASD and some participated in a sibling support group. The intervention approach of this project is unique in the dual focus on improving NT sibling's discrete play facilitation skills, but also addressing the NT sibling knowledge, perceptions and behavior related to having a sibling with ASD in the emotionally supportive context of a support group. NT siblings only participated in the first 3 weeks of the support group due the novel coronavirus (COVID-19) pandemic of 2020 2021. The study aimed to determine if there is a functional relation between sibling behavior skills training (BST) targeting use of play facilitation strategies and increases in (1) percentage of time spent in reciprocal play with their sibling with ASD, (2) frequency of NT sibling initiations, and (3) sibling fidelity of intervention implementation.

\section{Method}

\section{Participants}

Six sibling dyads were recruited to participate in the study in the Pacific Northwest. Each dyad consisted of a NT sibling and a child with ASD. Inclusion criteria for the NT siblings included falling in the age range of 5-13 years, parent report of displaying strong conversational speech, exhibiting developmentally appropriate play skills, and vocalizing their desire to increase their interactions with their sibling with ASD. When families had more than one NT sibling, parents were asked to nominate one sibling to participate in the study. Inclusion criteria for the child with ASD included falling in the age range of 3-11 years, having a medical diagnosis of ASD by an outside agency or an educational classification, and exhibiting symptoms of ASD including delays in communication, restricted and repetitive behaviors, and difficulty socializing. All participants' names are pseudonyms. (See Table 1.)

\section{Iago and Eric}

Iago, an 11-year-old NT sibling, had strong conversational skills and continuously modeled simple functional play skills for his brother (e.g., roll the ball, stack rings). Eric, a 3-year-old with a medical diagnosis of ASD, did not have any vocal verbal language and engaged in a high frequency of restricted and repetitive behaviors including pounding materials and repeatedly touching his cheek with his hand. Eric received an ASD medical diagnosis at the age of 2 and received intensive applied behavior analysis (ABA) services at the time of the study. He scored a 49.5 on the Childhood Autism Rating Scale-2 ${ }^{\text {nd }}$ Edition (CARS-2) parent interview, indicating severe autism symptoms (Schopler et al., 
Table 1 Participant characteristics

\begin{tabular}{|c|c|c|c|c|c|c|c|c|c|}
\hline Dyad & Child & Gender & Age & $\begin{array}{l}\text { CARS-2 } \\
\text { Score }\end{array}$ & Ethnicity & $\begin{array}{l}\text { Language } \\
\text { Spoken }\end{array}$ & $\begin{array}{l}\text { People in } \\
\text { household }\end{array}$ & $\begin{array}{l}\text { Highest education } \\
\text { level }\end{array}$ & Income \\
\hline \multirow[t]{2}{*}{1} & Iago & M & 11 & NA & Hispanic & $\begin{array}{l}\text { English/ } \\
\text { Spanish }\end{array}$ & 4 & High school & $>\$ 60,000$ \\
\hline & *Eric & M & 3 & 49.5 & & & & & \\
\hline \multirow[t]{2}{*}{2} & Freda & $\mathrm{F}$ & 5 & NA & White & English & 4 & MA & $>\$ 60,000$ \\
\hline & *Frodo & M & 8 & 32 & & & & & \\
\hline \multirow[t]{2}{*}{3} & Enoboria & $\mathrm{F}$ & 7 & NA & White & English & 4 & BA & $\$ 40,000-\$ 49,999$ \\
\hline & $*$ Effie & $\mathrm{F}$ & 7 & 30.5 & & & & & \\
\hline \multirow[t]{2}{*}{4} & Alice & $\mathrm{F}$ & 7 & NA & White & English & 6 & MA & $>\$ 60,000$ \\
\hline & $* J a c o b$ & M & 4 & 31.5 & & & & & \\
\hline \multirow[t]{2}{*}{5} & Lucius & M & 6 & NA & White & English & 5 & Associate & $>\$ 60,000$ \\
\hline & *Albus & M & 9 & 29.5 & & & & & \\
\hline \multirow[t]{2}{*}{6} & Arya & $\mathrm{F}$ & 8 & NA & White & English & 4 & BA & $>\$ 60,000$ \\
\hline & *Walden & M & 10 & 36.5 & & & & & \\
\hline
\end{tabular}

Note. * Indicates child diagnosed with ASD

2010). Iago did not participate in the sibling support group due to scheduling conflicts.

\section{Freda and Frodo}

Freda, a 5-year-old NT sibling, had strong conversational skills and engaged in complex play (e.g., board games and sociodramatic play). Frodo, an 8-year-old boy, received a medical diagnosis of ASD when 6 years old. Frodo spoke in full sentences, but demonstrated difficulties engaging in turn taking, sharing materials, and listening to directions. Frodo would occasionally aggress towards his younger sister when frustrated or when he wanted to gain access to materials. Frodo scored a 32 on the CARS-2 parent interview, indicating mild to moderate autism symptoms. Freda attended all sibling support group sessions.

\section{Enoboria and Effie}

Enoboria, a 7-year-old NT sibling, had strong conversational skills and often negotiated with her sister to play something she also wanted to play. Enoboria had strong pretend play skills and would often lead the interactions to continue the play. Effie, Enoboria's twin sister, received a medical diagnosis of ASD at age 3. Effie spoke in full sentences, engaged in sociodramatic play, and displayed strong reading skills. She had difficulties playing activities that her sister picked and putting the
iPad away before play times. Effie scored 30.5 on the CARS-2 parent interview, indicating mild to moderate autism symptoms. Enoboria and Effie dropped out of the study in March 2020 after the training sessions concluded due to reasons concerning the COVID-19 pandemic. Enoboria attended all the sibling support group sessions.

\section{Alice and Jacob}

Alice, a 7-year-old NT sibling, demonstrated strong conversational and play skills, but did not know how to engage her younger brother. Jacob, a 4-year-old boy with ASD, received a medical diagnosis of ASD shortly before the study began. Jacob had one-to-two-word utterances, which mostly consisted of labeling items and toys (e.g., play food, colors). He engaged in repetitive play behaviors including pressing levers, cutting toy food, and matching colors. He would also become upset if toys got stuck and frequently knocked down or destroyed his sister's block towers and creations. Jacob scored on 31.5 on the CARS-2 interview, indicating mild to moderate autism symptomology. Alice attended two of the sibling support group sessions.

\section{Lucius and Albus}

Lucius, a 6-year-old NT sibling, demonstrated strong communication skills and engaged complex play 
including board games and sociodramatic play. Lucius engaged in parallel play with his brother but lacked interest in continuous reciprocal play. Albus, a 9-yearold boy who received a medical diagnosis of ASD at age 3 , spoke in full sentences; however, he had difficulties engaging in a back-and-forth conversation. He could play simple board games and engaged in sociodramatic play with toy animals. He had restricted interests including plumbing, garbage and recycling trucks, and sea animals. Most of his language during play times consisted of repetition of the same scripts (e.g., "the shark is going to eat you"). Albus scored a 29.5 on the CARS-2 parent interview, indicating mild to moderate autism symptoms. Lucius also had a NT twin sister, Pansy. However, the mother nominated Lucius for the intervention study. Lucius and his twin sister Pansy both attended the sibling support group sessions.

\section{Arya and Walden}

Arya, an 8-year-old NT sibling, had strong verbal communication skills and appeared to enjoy engaging in pretend play with her brother. Walden, a 10-year-old boy with ASD and Fragile X syndrome, had strong verbal communication skills and could speak in full sentences and answer questions. He also engaged in sociodramatic play using dolls and dollhouses. He received an ASD medical diagnosis at 5 years. Walden had high levels of energy (e.g., frequently moving his body, talking at a fast pace, swiping materials off the table, screaming) and would frequently engage in scripted speech. Walden scored a 36.5 on the CARS-2 parent interview, indicating severe autism symptomology. Arya did not attend the sibling support group due to scheduling conflicts.

\section{Interventionists}

The first author delivered the intervention package to all sibling dyads and led the sibling support group. The first author has a master's degree in special education, is a board certified behavior analyst (BCBA), and is completing a Ph.D. in special education. Two undergraduate research assistants supported the interventionist during behavior skills training sessions and at the sibling support group. Both undergraduate students had experience working with children with ASD and had knowledge about applied behavior analysis.
Settings

Prior to the onset of the study, parents selected the setting of the intervention at either their family home or the Autism Center on a university campus. Freda and Frodo, Alice and Jacob, Lucius and Albus, and Arya and Walden participated in the play sessions at their homes. For the dyads who completed the study at home, experimental sessions were conducted where indoor play usually occurred (e.g., table, playroom, child bedroom). Iago and Eric and Enoboria and Effie attended their play sessions at the Autism Center on campus. The sessions at the Autism Center were carried out in a playroom with a big table and chairs, a large rug, and shelving and curtained cabinets with toys to minimize distractions. The selected toys were placed on the table for use by the children. The interventionist delivered the sibling support group at the University Autism Center. Behavior skills training sessions occurred at the participant's homes or at the University Autism Center depending on the family's preference. Due to onset of the COVID-19, the interventionist delivered the intervention to participating families in differing modalities (exclusively in person, partly in person, or hybrid) depending on progress towards completion of the study procedures at the time of the shelter-in-place order. Following shelter-in-place orders, the interventionist used telehealth to implement all remaining experimental sessions and assessments.

\section{Materials}

Play materials were provided for sibling dyads based on child preferences determined by the information from the reinforcer inventory and multiple stimulus without replacement (MSWO) preference assessment (Carr et al., 2000). Toy sets were provided to dyads based on the children's developmental play level and preference. All play sets included four toys and had one turn-taking game (e.g., Kerplunk ${ }^{\mathrm{TM}}$ or Pop the PigTM), one set of pretend play materials (e.g., play food set, castle and dolls), and one set of manipulative toys (e.g., blocks or Magna-Tiles ${ }^{\circledR}$ ). The same individualized play sets for each dyad were used during baseline, training, and intervention (see Supplementary Material for details). 


\section{Hardware and Software}

During baseline sessions conducted in the family's home or at the university setting, the interventionist used a MacBook Pro laptop to record video probes during play sessions for later data collection. All telehealth intervention sessions were conducted using Zoom $^{\mathrm{TM}}$ Video Communications Inc. platform on a HIPAAcompliant account (Zoom, 2020) and recorded for data collection. The interventionist initiated the intervention session from the university clinic using a MacBook Pro laptop with a built-in web camera. The interventionist used the internal microphone and speakers of the laptop to transmit two-way audio communication during sessions. During telehealth implementation of the intervention, caregivers used a personal tablet or laptop and their home internet connection during the play sessions to transmit and receive audio-visual communication occurring during the session. In particular, Freda and Frodo and Alice and Jacob used a laptop in their play sessions. The parent placed the laptop on a table or dresser with the built in web camera pointed downwards to a rug/mat where the children played. Lucius and Albus and Arya and Walden used tablets during the play sessions. Parents propped tablets on the surface of a coffee table or kitchen table and aimed the built in web camera towards the siblings playing. When Arya and Walden played on the kitchen table, the parent relocated the tablet to $3-5 \mathrm{ft}$ away from the children on the same table. Parents and siblings could see and hear the researcher throughout the session on their device using the internal speakers of their device.

\section{Dependent Variables and Interobserver Agreement}

The dependent variables in this study included percentage of reciprocal play, sibling frequency of initiations, and sibling use of play strategies.

\section{Reciprocal Play}

Reciprocal play was defined as siblings being within $3 \mathrm{ft}$ of each other and both engaging in the same activity in interdependent or shared play. Reciprocal play included handing materials to the sibling (e.g., giving the dice during a board game or pretending to feed the stuffed animals) or talking about the same activity (e.g., "Look, my car is red too!"; MacDonald et al., 2009). A 10-s whole-interval procedure was used to record reciprocal play. The percentage of reciprocal play was calculated by dividing the number of intervals with play by the total number of intervals and then multiplying that number by 100 to obtain a percentage.

\section{Frequency of Positive Initiations}

Initiations were defined as the NT sibling spontaneously asking a question (e.g., "Is it my turn?"; "Do you like the ball?"), making a positive comment, verbally requesting an item, or providing an invitation to play (e.g., "Come play"; "Look at this"). To be coded as an initiation, communication acts needed to be directed at the child with ASD. Nonverbal initiations such as pointing, handing materials, or high fives were not coded as initiations. Responses to a question were not coded as an initiation, but were coded as reciprocal play. Furthermore, negative initiations (e.g., "Stop that!") were not coded as an initiation. The frequency of positive initiations was tallied for each min throughout a 10-min sample and graphed.

\section{Sibling Use of Play Strategies}

Sibling use of targeted play strategies was measured to establish if NT siblings learned to implement the strategies taught during the BST phase. A four-item checklist with the operational definitions of the play skills was used to calculate the percent of global ratings of each skill. Use of skills in the procedure was scored by recording if the sibling independently (1) followed the child with ASD lead or used the provided choice wheel, (2) obtained their sibling's attention before providing play directions, (3) shared information and persisted during play, (4) and delivered praise. Each skill was rated on a 3-point scale of none, some, or most. A global score was given for each skill at the end of the 10-min session. None was scored as 0 points, some was scored as 1 point, and most was scored as 2 points. If the sibling used all four strategies most of the time, they would score 8 points. The total score was divided by 8 and multiplied by 100 to produce a percentage global rating of strategy use.

\section{Interobserver Agreement (IOA)}

Data were collected by two trained research assistants. Prior to the study, the research assistants were trained to reach a $90 \%$ agreement criterion on whole interval, 
frequency recording, and fidelity procedures. Training included directions on the dependent measures and practice using pen and paper with a stopwatch to record with the different measurement systems. Percentage of IOA was recorded during a minimum of $33 \%$ of all sessions in baseline, intervention, and follow-up across all sibling dyads. If IOA data were below $70 \%$ for two consecutive sessions, the data collector was retrained. The percentage of IOA for the percentage of reciprocal play was calculated for each sibling dyad by using exact count per interval calculation; that is adding the number of exact agreements and dividing by the total number of intervals, and then multiplying by $100 \%$. The more conservative block by block method (Page \& Iwata, 1986) was used to calculate IOA for frequency of initiations. Each min interval was scored and compared to obtain IOA. Intervals that have exact agreement were scored 1 . When intervals had disagreements, the smaller coefficient was divided by the larger coefficient to obtain a score (i.e., $2 / 4=0.5$ ). The interval scores were added and divided by the total number of intervals. Percentage of IOA for play strategies used was calculated by marking exact agreements or disagreements for the use of each strategy and dividing that number by 4 (the total number of strategies).

Mean IOA scores for Iago and Eric were 91\% (range: $78 \%-100 \%$ ), $84 \%$ (range: $72 \%-97 \%$ ), and $86 \%$ (range: $75 \%-100 \%$ ) across conditions for percentage of reciprocal play, frequency of initiations, and percentage of global ratings of play strategies used, respectively. Mean IOA scores for Freda and Frodo were 90\% (range: 78\%-100\%), $77 \%$ (range: $70 \%-89 \%$ ), and $89 \%$ (range: $75 \%-100 \%$ ) across conditions for percentage of reciprocal play, frequency of initiations, and percentage of global ratings of play strategies used, respectively. Mean IOA scores for Alice and Jacob were 95\% (range: 90\%-100\%), $88 \%$ (range: $79 \%-100 \%$ ), and $88 \%$ (range: $50 \%-100 \%$ ) across conditions for percentage of reciprocal play, frequency of initiations, percentage of global ratings of play strategies used, respectively. Mean IOA scores for Lucius and Albus were $92 \%$ (range: $85 \%-100 \%$ ), 82\% (range: 79\%-100\%), and $84 \%$ (range: $50 \%-100 \%$ ) across conditions for percentage of reciprocal play, frequency of initiations, and percentage of global ratings of play strategies used, respectively. Mean IOA scores for Arya and Walden were $94 \%$ (range: $78 \%-100 \%$ ), $86 \%$ (range: $70 \%-$ $100 \%$ ), and $86 \%$ (range: $50 \%-100 \%$ ) across conditions for percentage of reciprocal play, frequency of initiations, and percentage of global ratings of play strategies used, respectively.

\section{Procedural Integrity}

Procedural integrity was measured to ensure the accuracy of implementation of the BST procedures implemented by the interventionist via videotapes for all sessions across all participants. The fidelity measures were calculated by taking the number of observed appropriate teaching behaviors divided by the number of behaviors listed in the BST protocol. The main steps of BST protocol include providing instructions about each skill, modeling the skill, letting participants practice the skill, and then providing feedback. Procedural integrity was $100 \%$ across the coaching sessions. IOA data were collected for each session and agreement was $100 \%$.

Procedural integrity was measured to ensure the accuracy of implementation of the support group session procedure via in vivo data collection for all sessions. The fidelity measures were calculated by taking the number of appropriate teaching behaviors divided by the number of behaviors listed in the support group protocol. For the three completed support group sessions, procedural integrity was $100 \%$.

\section{General Procedures}

This study consisted of baseline, BST sessions for NT siblings, sibling-implemented play intervention and sibling support group, and maintenance sessions. Baseline and intervention sessions occurred biweekly for $30 \mathrm{~min}$ each session. During all sessions, 10-min video recorded probes were coded for dependent variables. Generalization probes of siblings' skill use and percentage of reciprocal play across different toy sets were taken during all experimental phases. All baseline sessions and BST training sessions occurred face-to-face in the homes or at the clinic. The interventionist delivered the sibling support group weekly at the University Clinic and the start date of the sibling support group coincided with when Freda and Frodo completed the BST session.

Play sessions switched to telehealth delivery of the intervention package from the start of the government mandated shelter-in-place order in March 2020 because of COVID-19. Sheltering in place refers to staying home as much as possible, only leaving your home for essential activities, and not hosting/attending any gatherings. Two weeks following the shelter-in-place order, the 
interventionist delivered the toy sets to the children's homes and instructed parents to set up their videoconferencing technology and materials prior to each session as well as deliver the stickers and prizes at the end of each session. The remaining weeks of the sibling support group were discontinued due to the COVID-19 pandemic.

Due to the staggering nature of the multiple baseline design and the implementation of intervention at different points in time, dyads received different doses of inperson and telehealth intervention. In particular, Iago and Eric completed all intervention sessions in person and did not receive any intervention via telehealth. Freda and Frodo switched to telehealth delivery of the intervention after the fifth intervention point and the remaining intervention sessions were delivered via telehealth. Enoboria and Effie completed baseline sessions and BST in person and then dropped out of the study due to the switch to telehealth delivery of the intervention. Alice and Jacob received one intervention session in person and received all remaining intervention sessions via telehealth. Likewise, Lucius and Albus completed one intervention session in person and then the remaining intervention sessions were delivered via telehealth. Arya and Walden received all intervention sessions via telehealth.

\section{Baseline}

Baseline data were collected for all sibling dyads. During the first $10 \mathrm{~min}$, the interventionist set up the individualized toy set and video camera in a playroom, living room, or designated play space and children freely interacted with the toys. The next 10 min was recorded for data collection of the dependent variables. After, the interventionist said "It is now time to play with your brother or sister by yourselves for $10 \mathrm{~min}$. I can play and talk with you after." During this time, adults did not interact with the children and responded to their initiations with "I can talk to you after you are done playing." If parents reported aggressive behavior for either of the children during intake, the interventionist created a safety plan to keep children safe including prompting children to take turns, reminding children to use their words, and leading a child from the area if in harm's way. Two of the sibling dyads required a safety plan. Only one of the sibling dyads needed prompting to use safe hands throughout baseline and intervention sessions. Removal of the NT sibling only occurred during one baseline session. After the siblings played together for $10 \mathrm{~min}$, adults could play and interact with the children using the toy set or other toys around the house. Generalization probes were taken in the same format, but parents set up toys they have from home including one turn taking game, one set of pretend play items, and one manipulative toy. For sibling dyads who attended sessions at the University Autism Center, parents brought in a set of toys from their home.

\section{Behavior Skills Training}

The interventionist implemented behavior skills training (BST; Parsons et al., 2012) with the NT siblings only. The child with ASD did not receive any explicit instruction during the study. BST for the four different play strategies included: (1) following the lead of the child with autism or using a provided choice wheel listing the available toys/activities, (2) obtaining the attention of the child with autism before providing simple directions, (3) sharing information and persisting through play, and (4) delivering praise to the child with autism. (See Table 2.) The training sessions provided the siblings with a definition of the new skill, the interventionists modeled the skill, and allowed the sibling to practice the skill with feedback from the interventionist. All siblings needed to reach $100 \%$ fidelity during the roleplay probes with the interventionist before practicing these skills with their siblings. On average, training sessions lasted from $45 \mathrm{~min}$ to $1 \mathrm{hr}$. To increase motivation during the teaching phase, siblings were provided with a laminated play tips sheet in which they collected small stickers as rewards on the back of the sheet. Stickers were earned during teaching sessions by sitting nicely, answering questions, and correctly role playing the skill. At the end of the teaching session, the siblings redeemed their stickers for a small prize (e.g., one small container of slime, one small toy animal).

\section{Intervention}

All sibling dyads received the sibling-mediated play intervention and four of the NT siblings participated in the support group. Prior to the play intervention, the interventionist reminded the NT sibling of each of the play tips using a visual sheet and asked if they had any questions. The visual sheet had a list of the four bulleted strategies. The interventionist reminded the NT sibling that they could earn stickers and a prize at the end for 
Table 2 Sibling play strategies

\begin{tabular}{|c|c|c|}
\hline Intervention Strategy & Definition & Examples \\
\hline $\begin{array}{l}\text { Following the child's lead } \\
\text { and giving choices OR } \\
\text { using a choice wheel }\end{array}$ & $\begin{array}{l}\text { Following the child's lead: playing with what the } \\
\text { child is already playing with or interested in. } \\
\text { Giving choices: offering two different activities or } \\
\text { materials to play with } \\
\text { *Choice wheel: each child takes turns picking the } \\
\text { activity on the choice wheel for both children to } \\
\text { play with } \\
\text { (*The choice wheel will only be used for dyads where } \\
\text { the child with ASD can engage in activities that are } \\
\text { picked by the brother or sister) }\end{array}$ & $\begin{array}{l}\text { Example: the child with ASD is playing with } \\
\text { playdough so the NT sibling grabs some playdough } \\
\text { to build. } \\
\text { Example: NT sibling asks, "Do you want to play the } \\
\text { slinky or magna-tiles?" } \\
\text { Example: Child } 1 \text { is the leader first and picks the } \\
\text { dollhouse on the choice wheel for the first } 4 \text { min. } \\
\text { Both children engage with the dollhouse for that } \\
\text { time. Next, Child } 2 \text { picks blocks on the choice } \\
\text { wheel and both children play with the blocks for the } \\
\text { next } 4 \text { min. }\end{array}$ \\
\hline $\begin{array}{l}\text { Obtaining attention before } \\
\text { providing simple } \\
\text { instructions }\end{array}$ & $\begin{array}{l}\text { Getting attention: sibling must have the child's } \\
\text { attention on either the stimulus or the sibling prior } \\
\text { to presenting directions or a prompts } \\
\text { Simple instructions: sibling questions or instructions } \\
\text { must be simple, clear, and appropriate to the } \\
\text { activity }\end{array}$ & $\begin{array}{l}\text { Example: NT sibling says their brother or sister's } \\
\text { name, taps them on the shoulder, or positions their } \\
\text { body across from the child } \\
\text { Example: NT siblings waits for attention before } \\
\text { saying "Put the piece on" or "Roll the car here" }\end{array}$ \\
\hline $\begin{array}{l}\text { Sharing information and } \\
\text { persisting through play }\end{array}$ & $\begin{array}{l}\text { Sharing information: talking about what they are } \\
\text { doing or narrating what the child with ASD is doing } \\
\text { Persisting through play: the NT sibling continues to } \\
\text { provide prompts and plays even with rejections and } \\
\text { tries presenting toys in multiple ways }\end{array}$ & $\begin{array}{l}\text { Example: NT sibling narrates play including "I am } \\
\text { building a garage for the cars" or "The slinky is } \\
\text { coming to get you." } \\
\text { Example: NT sibling gives brother a coin for the cash } \\
\text { register and he puts it down. The sibling models } \\
\text { putting the coin in the cash register and gives } \\
\text { another coin to his brother. }\end{array}$ \\
\hline Providing praise & $\begin{array}{l}\text { Providing praise: reinforcing positive play, turn } \\
\text { taking, and sharing materials with verbal } \\
\text { statements, high-fives, or * pairing with edible treats } \\
\text { * Small edible treats paired with verbal statements for } \\
\text { children with ASD who need an extra } \\
\text { reinforcement schedule }\end{array}$ & $\begin{array}{l}\text { Examples: NT sibling asks her brother to put the pink } \\
\text { piece on top of the house. After her brother puts the } \\
\text { pink piece on top, she says "Good job!". } \\
\text { The children are playing with play food and the child } \\
\text { with ASD hands her sister the cake. The NT sibling } \\
\text { says "Thanks. I love the cake!" } \\
\text { The child with ASD builds a shark tank for the sharks } \\
\text { and his brother says "Woah! That is really cool." }\end{array}$ \\
\hline
\end{tabular}

using the play tips. The interventionist also reminded the child with ASD that they could also earn stickers or a prize if they stayed in the room and played with their sibling. Priming and material set up occurred for the first $10 \mathrm{~min}$ of the session and then the interventionist gave the direction of "It is now time to play with your brother or sister by yourselves for $10 \mathrm{~min}$. I can play and talk with you after." Following completion of the 10-min probe, the interventionist gave the NT sibling feedback on each skill and then passed out prizes to the children. If fidelity of the NT sibling fell below $75 \%$ for two consecutive sessions, the interventionist provided verbal prompts every min in the subsequent intervention session to remind the NT sibling of the play skill(s) they needed to use.

Four of the NT siblings also participated in a weekly support group that coincided with the end of baseline sessions and the play intervention. The support group consisted of semi-structured content delivery for $50 \mathrm{~min}$ across 8 weeks. The interventionist led topics using a written curriculum, facilitated discussions, led group activities, and encouraged siblings to share experiences. Although support group sessions were planned over 8 weeks, only 3 of the weeks were conducted. The topics included Welcome Session (Week 1), Autism Characteristics (Week 2), and Attention and Fairness (Week 3). Each session topic had a short take home activity for children (with their parent supporting as needed) to complete outside of the session. For instance, a takehome activity included coming up with their own superpower and thinking about what superpower their sibling had. The interventionist reviewed the takehome activities at the start of the next session. The structure of each support group lesson included an ice 
breaker, review of the take-home activity, presentation of the leading question, group reading of a researcher created comic strip addressing the session topic, a group activity focused on the topic, discussion and question time, wrap up and introducing the take-home activity for the following week.

\section{Maintenance}

Follow-up play probes were recorded two weeks after intervention for the following dyads: Freda/Frodo, Alice/Jacob, and Lucius/Albus. During the maintenance phase, no priming occurred before the play session and no rewards were delivered after the play session. Follow-up sessions also used toys at the home.

\section{Social Validity}

Parent and NT sibling surveys and interviews post intervention provided a measure of social validity. Parents and NT siblings were asked to rate the acceptability, effectiveness, and feasibility of the intervention goals, procedures, and outcomes using an adapted version of the Treatment Acceptability Rating Form-Revised (TARF-R; Reimers \& Wacker, 1988). NT siblings received an adapted version of the parent social validity questionnaire and it was presented via PowerPoint slides by the researcher. Parents received a printed version of the survey and filled out the form independently. Parents and NT siblings that received the sibling support group were asked additional questions specifically about the acceptability and enjoyment of the support group.

\section{Experimental Design and Analysis}

The research design was a concurrent multiple-baseline design (MBD) across sibling dyads (Kazdin, 2011; Kratochwill \& Levin, 2015) to assess the effectiveness of the sibling-implemented intervention on reciprocal play, initiations directed towards the child with ASD, and sibling use of targeted play strategies. The interventionist conducted a formal visual analysis as the study progressed on the level, trend, variability, immediacy effect, and overlap of data points between phases to evaluate basic relations between the dependent variables on sibling behavior and the intervention for each participant and whether a functional relation between the intervention and the dependent variables exists at the study level (Kazdin, 2011). Vertical analysis was also conducted across the dyads to assess the potential for behavioral covariation. Vertical analysis allows for the examination of the consistency of data patterns to the extent to which phases with similar conditions (e.g., baseline or intervention) were associated with similar data patterns.

If visual analysis determined clinically significant change, Tarlow's (2017) nonparametric, nonoverlap index Tau-U was calculated using the Single-Case effect size online calculator (Version 0.5 ) available at https://jepusto.shinyapps.io/SCD-effect-sizes/ (Pustejovsky \& Swan, 2018), which includes an adjustment for baseline time trends. For each of the dependent variables in this study, an increase was desired so Tau-U was calculated as Kendall's $S$ statistic for comparison between the A and B phases, plus Kendall's $S$ statistic for the A phase data scaled by the number of observations in each $\mathrm{A}$ and $\mathrm{B}$ phase. In a MBD, visual analysis is conducted during baseline to verify stable patterns of documented issue, and to ascertain the absence of therapeutic trend which would suggest an extraneous variable affecting participant responding. This particular index and calculator was selected due to the correction of baseline trends, which aligns with the design logic of a MBD and our suspicion that our baseline procedures could alone result in improvements in some participants by virtue of structured sibling interaction. Tau-U was reported for all dyads who completed intervention. Tau$\mathrm{U}$ cannot be reported for dyad 3 because they did not complete intervention.

Between case standardized mean difference (BCSMD) was also calculated to determine effect sizes between cases for each dependent variable. This is a parametric approach to determine the magnitude of the functional relation separately for each case in a study by dividing the difference in mean outcomes by the pooled standard deviation of the outcome among participants. The following assumptions in the data were met: (1) baseline data were stable and had no increasing trend, (2) the intervention produces a change in the dependent variable, (3) the intervention effect is constant across cases, and (4) the outcome is normally distributed about case mean levels (Barton et al., 2019). Cohen's $d$ was used to interpret the findings. Per convention, effect sizes of $d=0.2, d=0.5$, and $d=0.8$ were considered small, medium, and large effects, respectively (Cohen, 1988). To calculate Tau-U and SMD effect size, the Single-Case effect size online calculator 
(Version 0.5) was used from https://jepusto. shinyapps.io/SCD-effect-sizes/ (Pustejovsky \& Swan, 2018).

\section{Results}

Iago and Eric

Data are presented in the top panels of Figs. 1 and 2, indicating strong basic effects for intervention and increased percentage of reciprocal, sibling use of play strategies, and frequency of sibling initiations. Iago and Eric had low levels of reciprocal play during baseline sessions $(M=4.35 \%$, range: $0 \%-11.67 \%)$. Iago did use some of the strategies during baseline sessions, but there was a decreasing trend in the number of play strategies used ( $M=37.5 \%$, range: $25 \%-50 \%)$. After training, there was an immediate increase in his use of play strategies ( $M=85 \%$, range: $75 \%-87.5 \%)$. During intervention, there was an increasing trend for the percentage of reciprocal play $(M=23.66 \%$, range: $13.3 \%-$ $38.33 \%$ ). No overlap was observed between baseline and intervention for the frequency of sibling initiations. There was an immediate increase in the total sibling initiations during intervention $(M=54.4$, range: $50-$ $62)$. Maintenance and generalization probes were not conducted during intervention for this dyad. Tau-U was calculated for percentage of reciprocal play (Tau $=$ $1.00)$, fidelity of intervention (Tau $=1.00)$, and frequency of sibling initiations ( $\mathrm{Tau}=0.92$ ) indicating a large effect for each dependent variable.

\section{Freda and Frodo}

Data are presented in the second panels of Figs. 1 and 2, indicating strong basic effects between intervention and increased percentage of reciprocal, sibling use of play strategies, and a moderate basic effect for frequency of

Fig. 1 The percent of reciprocal play and percentage of siblings' global use of strategies across sibling dyads. Open circles and triangles represent generalization probes. The tick represents 2 weeks' time elapsed, and the dotted phase change line represents the change of intervention delivery to telehealth

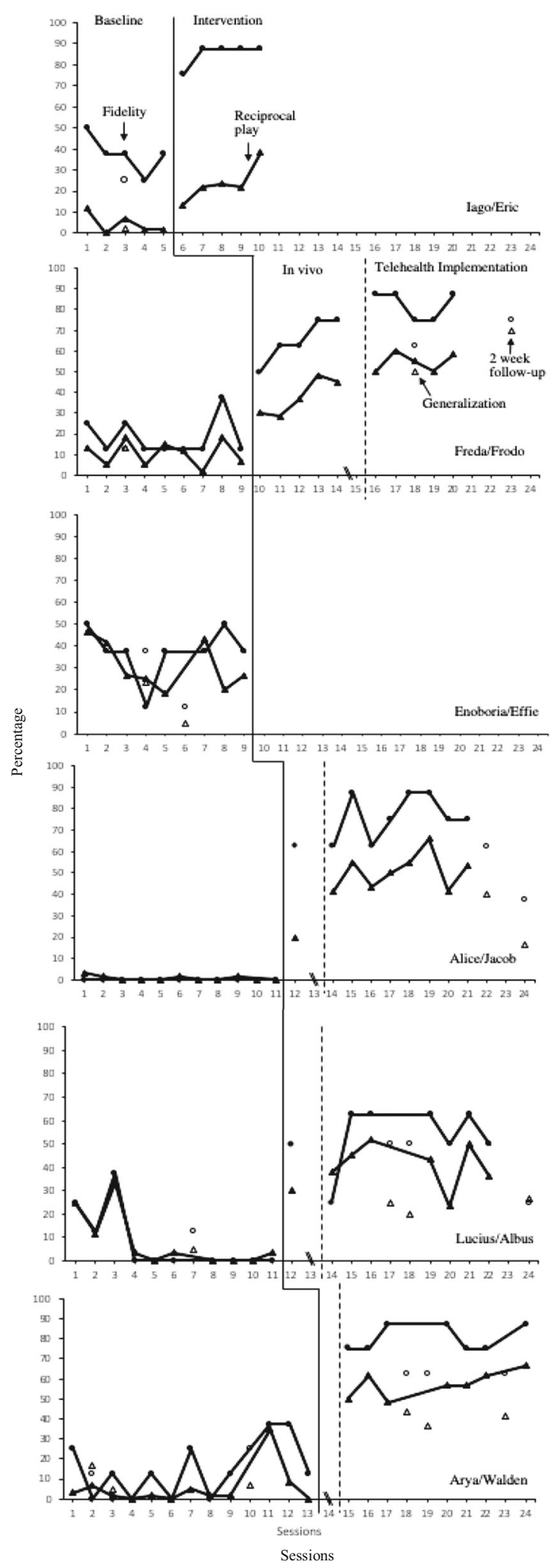




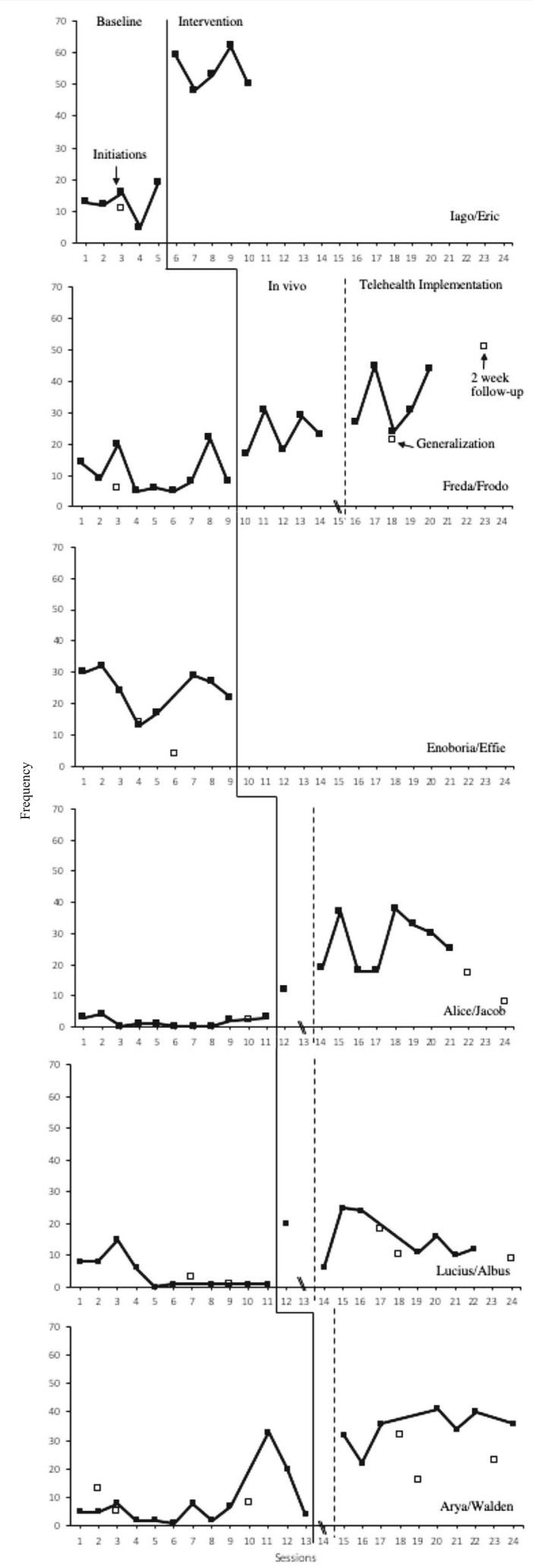

Fig. 2 Frequency of NT sibling initiations. Open squares represent generalization probes. The tick represents 2 weeks' time elapsed, and the dotted phase change line represents the change of intervention delivery to telehealth

sibling initiations. Freda and Frodo had low levels of reciprocal play during baseline sessions $(M=10.55 \%$, range: $5 \%-18.33 \%)$. Freda also used few play strategies during baseline ( $M=18.05 \%$, range: $12.5 \%-37.5 \%)$. After training, there was an increasing trend for both reciprocal play $(M=37.66 \%$, range: $30 \%-48.33 \%)$ and use of play strategies $(M=65 \%$, range: $50 \%-75 \%)$ during in-vivo intervention sessions. During telehealth intervention sessions, the use of play strategies remained at a stable level $(M=82.5 \%$, range: $75 \%-87.5 \%)$ as well as the percentage of reciprocal play $(M=54.66 \%$, range: 50\%-60\%). During baseline, Freda had relatively low, but variable initiations towards her brother $(M=$ 10.77, range: $8-22$ ). Following training, the frequency of sibling initiations remained variable, however, there was an increasing trend throughout the intervention phase $(M=28.9$, range: $17-44)$. Reciprocal play and the use of play strategies remained at a high level at the 2-week follow up probe. Furthermore, the frequency of sibling initiations increased during the 2-week follow up probe compared to intervention and baseline sessions. Tau- $\mathrm{U}$ was calculated for percentage of reciprocal play $(\mathrm{Tau}=1.00)$, fidelity of intervention $(\mathrm{Tau}=1.00)$, and frequency of sibling initiations (Tau $=0.93)$ indicating a large effect for the dependent variables.

\section{Enoboria and Effie}

Data are presented in the third panels of Figs. 1 and 2. Baseline data across all dependent variables in highly variable. During baseline, Enoboria and Effie could play together for extended amounts of time $(M=31 \%$, range: 20\%-46.67\%). Enoboria also used multiple play strategies $(M=37.5 \%$, range: $12.5 \%-50 \%)$ and had a relatively high level of initiations ( $M=24$, range: $13-32)$ in the baseline phase. Enoboria and Effie dropped out of the study and therefore did not receive any intervention.

Alice and Jacob

Data are presented in the fourth panels of Figs. 1 and 2 indicating strong basic effects between intervention and increased percentage of reciprocal, sibling use of play strategies, and frequency of sibling initiations. Alice and 
Jacob had very low levels of reciprocal play $(M=$ $0.83 \%$, range: $0 \%-3.33 \%$ ) and Alice did not use any of the play strategies during baseline. After training, there was an immediate increase in the level of reciprocal play $(M=77.32 \%$, range: $20 \%-65.96 \%)$ and the number of play strategies used $(M=75 \%$, range: $62.5 \%-87.5 \%$ ). During baseline, Alice had a low and stable level of initiations toward her brother $(M=1.22$, range: $0-4)$. Although the total initiations were more variable in intervention, the level of total initiations during telehealth intervention immediately increased ( $M=25.55$, range: $12-38)$. The frequency of initiations, percentage of reciprocal and play strategies used remained higher than baseline levels during the 2week follow up probe. Tau-U was calculated for percentage of reciprocal play ( $\mathrm{Tau}=1.00$ ), fidelity of intervention (Tau $=1.00)$, and frequency of sibling initiations $($ Tau $=1.00)$ indicating a large effect for the dependent variables.

\section{Lucius and Albus}

Data are presented in the fifth panels of Figs. 1 and 2 indicating moderate basic effects between intervention and increased percentage of reciprocal, sibling use of play strategies, and frequency of sibling initiations. In baseline, Lucius and Albus had a decreasing trend for percentage of reciprocal play $(M=8.88 \%$, range: $0 \%-33.33 \%)$. There was also a decreasing baseline trend for the percentage of play strategies utilized $(M=8.83 \%$, range: $0 \%-$ $37.5 \%)$. After training, there was an increase in level for both reciprocal play $(M=39.67 \%$, range: $23.33 \%-51.7 \%)$ and the percentage of play strategies used ( $M=53.13 \%$, range: $25 \%-62.5 \%)$. During telehealth intervention sessions, reciprocal play was variable and lower during generalization sessions. The percentage of play strategies used dropped during the first telehealth session and then increased to a higher and stable level. During baseline, the frequency of initiations was variable but relatively low ( $M=4.55$, range: $0-15)$. In intervention, the frequency of sibling initiations remained highly variable and had a decreasing trend $(M=$ 15.5, range: 6-25). Furthermore, there was a decrease in reciprocal play and sibling use of strategies during the 2 -week follow up probe. Tau-U was calculated for percentage of reciprocal play $(\mathrm{Tau}=$ $1.00)$, fidelity of intervention $(\mathrm{Tau}=1.00)$, and frequency of sibling initiations $(\mathrm{Tau}=1.00)$ indicating a large effect for the dependent variables.

Arya and Walden

Data are presented in the bottom panels of Figs. 1 and 2 indicating strong basic effects between intervention and increased percentage of reciprocal, sibling use of play strategies, and a moderate effect for frequency of sibling initiations. In baseline, Arya and Walden had a low level of reciprocal play with some high variable baseline points $(M=5.39 \%$, range: $0 \%-37.5 \%)$. Arya did use some of the play strategies during baseline, but the use was variable $(M=14.58 \%$, range: $0 \%-37.5 \%)$. However, after training, there was an immediate increase in both reciprocal play $(M=57.38 \%$, range: $48.33 \%-$ $66.67 \%)$ and the percentage of play strategies used $(M$ $=80.35 \%$, range: $75 \%-87.5 \%$ ). During baseline, the frequency of initiations was low with the exception of two high data points $(M=8.08$, range: $1-33)$. After training, total initiations remained a stable and higher level compared to baseline ( $M=34.42$, range: $16-41)$. The generalization and follow-up probe had lower levels of reciprocal play, sibling use of strategies, however, it was still higher than baseline levels. Tau-U was calculated for percentage of reciprocal play (Tau $=0.99$ ), fidelity of intervention (Tau $=0.83$ ), and frequency of sibling initiations $(\mathrm{Tau}=0.82)$ indicating a large effect for the dependent variables.

\section{Between Case Effect Sizes}

BC-SMD is a between case effect size for single case designs (Valentine et al., 2016). The independent variable had a large effect on reciprocal play $(d=3.34$ [1.91, 4.77]), NT sibling fidelity of implementation $(d=2.91$ $[2.04,3.79])$, and NT sibling frequency of initiations $(d$ $=1.79[0.86,2.72])$.

\section{Social Validity}

Three of the five parents returned the social validity forms, and four of the five NT siblings completed the social validity questionnaire. The social validity forms were split into two different sections, the play intervention and the support group. The play questionnaire included ten different items, and the support group section included four separate items. Each item had a 5-point Likert scale ranging from "strongly disagree" to 
"strongly agree." Overall, parents rated the play intervention very highly $(M=4.8$, range: $4-5)$ in terms of effectiveness, feasibility, and likability. In particular, one parent commented "I have seen my children take turns better and be more willing to play what the other person wants." The NT siblings also rated the play intervention highly ( $M=4.3$, range: $3-5)$. The NT children enjoyed learning about the play tips and thought they played with their sibling with ASD more after the intervention. Some siblings felt neutral about feeling closer to their sibling after the intervention and only sometimes used the play tips after the intervention ended. Most of the siblings commented that their favorite part was "playing with new toys" and "playing with their brother or sister."

Parents and siblings also rated the three weeks of the sibling support group highly. Although the sibling support group was not completed as intended, parents liked the take-home activities and materials. Overall, parents rated the support group very highly $(M=4.75$, range: 4 5 ) in terms of feasibility and likability. Parents strongly agreed the support group was beneficial and the take home activities were engaging and relevant. One parent commented "The content planned in the binders was creative, engaging, and relevant." Overall, it appeared that siblings liked attending the support group and enjoyed being around other siblings with similar experiences $(M=4.33$, range: $3-5)$. Siblings strongly agreed that they learned more about ASD and liked being around other siblings with similar experiences.

\section{Discussion}

Sibling-mediated interventions have been used to increase play and other outcomes for children with ASD; however, few studies have reported the outcomes of participating NT siblings and those that have solely reported fidelity of implementation (Bene \& Lapina, 2020; Shivers \& Plavnick, 2015). The current study adds to this literature by reporting the effects of an intervention package on joint sibling outcomes of reciprocal play as well as the more commonly reported fidelity of implementation outcomes (i.e., NT sibling use of play strategies and sibling initiations). Overall, the results of this single-case design indicated that brief sibling training on play strategies effectively increased NT sibling use of targeted strategies and positive reciprocal sibling play. A key finding of this study is that efficiently training only the NT sibling using BST can lead to increases in reciprocal play between the siblings. Moreover, positioning the NT sibling as a change agent during shared play activities with their sibling with ASD has the potential of improving the relationship over time through paired reinforcement via mutually enjoyable activities. Although a future empirical question, this type of intervention may ultimately assist in improving the sibling relationship for children with and without ASD.

In addition, although COVID-19 resulted in the closure of the university clinic and affected implementation, three sibling support group sessions were provided to the NT siblings to address the potential need for informal social supports (Hastings, 2003). Our findings suggest that the addition of a sibling support group with the sibling play intervention may be beneficial to NT siblings. Social validity questionnaire results from those NT siblings attending the three sibling support group sessions suggests that the addition of a support group to behavioral intervention packages for siblings may be feasible, acceptable, and seen as effective in addressing the need for emotional support from other children with similar experiences. In addition, NT siblings appeared to enjoy having the opportunity for interactions with other siblings who had similar experiences with their sibling with ASD.

\section{Sibling Reciprocal Play}

During baseline, most of the sibling dyads independently played with different toys and switched toys midway through the session. Of the few sibling dyads that did interact during baseline, most interactions consisted of exchanging toys or engaging in parallel play. All sibling dyads had increases in the average percentage of reciprocal play after training. These findings extend past research on siblingmediated interventions as past studies have failed to report outcomes for the sibling or the dyadic interaction between the siblings (Banda, 2015; Shivers \& Plavnick, 2015). However, this study did not examine continued reciprocal play after the 2-week follow up. Although the percentage of play maintained for those dyads participating in the follow up, the distal impact of an intervention like this focused on increasing reciprocal play is of interest.

In addition, the implementation of the play sessions via telehealth did not appear to negatively 
affect reciprocal play for any of the sibling dyads. This finding is not surprising given the number of similarities between the intervention when conducted in person and when conducted via telehealth in the family's home (i.e., the exact toy sets were used, the exact prompts were used to initiate and stop the session, the researcher was present in both settings). Our findings do not suggest substantial changes in sibling behavior at home during telehealth sessions when compared to the in person delivery of the intervention; however, based on our clinical experience, we suggest that researchers conducting telehealth research with siblings might want to include prestudy questions for siblings and the parents followed by observations of typical sibling play in their home to identify potential concerns such as aggression or unkind comments that would require intervention adaptation.

Furthermore, we anecdotally observed that most of the children with ASD engaged with a greater variety of toys during intervention sessions compared to baseline. The toy sets were selected based on parent- and child-completed reinforcer inventories and systematic preference assessments. During intervention, the children selected the play activities. The observed increase in variability during intervention sessions suggests a behavioral mechanism of change associated with the onset of the intervention. NT siblings may have acted as positive play role models and increased their sibling's play behavioral flexibility during play sessions. As an alternative, continued exposure to the novel toys over the course of the experimental sessions may have contributed to increased engagement. Studies of sibling intervention should consider collecting data on the observed developmental level of play and the variability in types of toys or activities engaged in alone and with their sibling to examine any potential indirect positive outcomes.

Initiations

NT sibling initiations were variable across sessions in baseline and intervention for most of the participants. Prior to intervention, NT sibling initiations were relatively infrequent, with most sessions having less than two initiations per min. The average number of initiations increased in intervention for all participants; however, there was overlap in the frequency of initiation between baseline and intervention for three of the participants. One reason for the variability of initiations may be due to what was coded as an initiation, as only vocal verbal initiations directed towards the child with ASD were counted. Other types of initiations like handing materials, pointing, or making animal/car animated noises were not counted as an initiation. These types of interactions were coded as reciprocal play; however, the definition used in this study may not have captured all types of sibling initiations.

\section{Sibling Use of Play Strategies}

BST and presession priming of the play strategies effectively increased NT sibling fidelity of implementation during the play sessions for all siblings. However, the siblings under the age of 7 took a longer to reach $75 \%$ of the play strategies used or never reached $75 \%$. Freda did not reach $75 \%$ of strategies used until the fourth play session and then remained above $75 \%$ for the rest of intervention. Lucius had lower levels of fidelity of implementation compared to the rest of the participants. He remained below $62.5 \%$ in the strategy use even with priming and prompting during the play session. These findings can be partially explained by distractions in his household (e.g., neighbors running around, other siblings wanting to use the toys) or also his young age. Younger children like Lucius may benefit from more intensive prompting and modeling during the play sessions to use the strategies consistently.

It is also interesting to note that none of the siblings ever reached $100 \%$ fidelity of implementation (i.e., using all the strategies most of the time) suggesting that a lower dosage of strategy use can increase reciprocal play. Most of the siblings scored the lowest on the provision of descriptive praise across baseline and intervention sessions. Verbal praise might be one mechanism of how reciprocal play is reinforced; however, other potentially reinforcing consequences could include the continuation of play, smiling and other positive facial affect, or the addition of something novel in the interaction. These types of interactions might be more common during reciprocal play given that children typically play because the interactions are experienced as fun, allow opportunities to act out more adult roles, and reduce stress (Hurwitz, 2002; Isenbery \& Quisenberry, 1988; Tsao, 2002) and not because peers explicitly compliment their play or social skills. Therefore, continuous verbal praise may not be socially valid for sibling play. 
Limitations and Future Directions

There are several limitations in this current study. First, the sudden change to the telehealth delivery of intervention limits the ability to draw conclusions about the effectiveness of the intervention package because of the change in the modality of intervention. There are only two demonstrations of a basic effect for the in-vivo delivery of the play intervention for the first two sibling dyads. Another limitation is the attrition associated with the COVID-19 pandemic and switch to telehealth. Due to the shift in delivery modality paired with the effects of the government mandated shelter-in-place order for the participating families, Iago and Eric did not complete any telehealth play sessions and the third dyad dropped out of the study with no intervention sessions completed. Other threats to internal validity include spending more time at home, attending school online, and having parents work from home. This sudden switch limits the internal validity of the study, but telehealth implementation of the play intervention appeared to be effective. It is promising that most sibling dyads responded well to telehealth sessions. It is important to note that all baseline sessions and BST sessions were implemented in person, so the effectiveness of virtual training to NT siblings cannot be determined. Also, because previous sessions were in person, siblings already knew the routine and structure of the play sessions and rapport was already built with the siblings and families. A third limitation of this study is the low dosage of, and lack of sibling participation in, the sibling support group. Limited conclusions can be drawn from the support group. Fourth, low IOA scores were obtained for sibling use of play facilitation strategies. This could be due to the limitations of what researchers can reliably code via telehealth without the use of more sophisticated cameras and microphones to capture the interactions between siblings. Another reason for low IOA scores for sibling fidelity could be due to the way IOA was scored globally for each strategy. A partial interval system for use of strategies for each min would more accurately capture the total use of strategies and would also be easier to reach agreement. Finally, although social validity measures were completed by NT siblings and a caregiver, the social validity measures were not completed by the children with ASD. The absence of the children with ASD perceptions and acceptability of the intervention is a limitation of this study.

Questions were raised in the review process about the naturalness of providing prizes for both NT siblings and the children with ASD. It could be a concern that siblings showed increases in fidelity of implementation simply to earn a prize, but rewards for following expected or newly learned behaviors can be commonplace in Western parenting culture. Furthermore, even mastered behaviors can wane in the face of extinction, thus parents should expect to need to continue to provide some form of reinforcement for appropriate sibling interactions. The addition of prizes and novel toys could have also safeguarded the possibility of putting an increased burden on NT siblings. None of the NT siblings appeared to experience any adverse effects during this study.

Future research should investigate the maintenance of sibling play while fading out a dense reinforcement schedule. Long-term maintenance and outcomes for both children in addition to reciprocal play are suggested for future research. Further research implementing the entirety of the intervention via telehealth is needed to document the effectiveness of this delivery modality in improving reciprocal play, but our findings suggest this may be a promising avenue for efficiently reaching underserved populations. Another important area of future research is exploring the pivotal skills for siblings to learn to increase positive play. In particular, it would be beneficial to run a component analysis (WardHorner \& Sturmey, 2010) of the common play strategies to identify which strategies have the largest impact on reciprocal play. It would also be beneficial for future research to document additional benefits for the child with ASD including joint attention, turn-taking and communication acts that were not measured in this study. Finally, researchers seeking to improve sibling play should explore the similarities and differences when play occurs between peers and siblings, in particular when there is a sizable gap in age.

Implications for Practice

Telehealth can be a preferred service delivery mode for increasing accessibility of interventions, overcoming geographic barriers, and reducing traveling times for 
both families and interventionists (Simacek et al., 2020). Synchronous telehealth intervention did allow for immediate instruction, modeling, and instantaneous feedback which proved advantageous when working with siblings. However, there are barriers to implementation of intervention via telehealth including engaging children to attend and listen, capturing play within the view of the camera, and the ability to address challenging behaviors. Interventionists will need to plan for ways to keep children engaged and build rapport through teleconferencing. Changing Zoom backgrounds with preferred interests, providing virtual tokens, and playing online games together are some strategies to increase child engagement. Successful remote delivery of sibling-mediated interventions may require parent involvement including the delivery of reinforcement and implementation of a behavior plan for challenging behaviors. Parent training may be an essential component for increasing positive sibling play. Furthermore, technology checks with families before the start of intervention can decrease technical difficulties and frustrations. Planning a Zoom call prior to the first intervention session where parents can set up the technology and mark (e.g., tape, sticker) positioning of the computer/ tablet to capture play was beneficial. Likewise, using visual zones (e.g., using a rug/table) to mark the area to stay and play within to ensure sibling interactions could be seen by the interventionist via Zoom was useful.

\section{Conclusion}

Although there are limitations with the present study, it appears that sibling-mediated play intervention in combination with a sibling support group is beneficial for NT siblings and their siblings with ASD. Increasing positive play between siblings may be especially important during the COVID-19 pandemic when more time is spent with one's family due to shelter-in-place orders affecting the provision of school and therapy as well as the reduced availability of organized social or recreational activities outside of the home. Results from this study suggest siblings can learn simple play strategies to use with their siblings to increase reciprocal play. Findings from this study are consistent with the existing literature in that siblings may be an ideal intervention agent to increase positive play for their siblings with ASD.
Acknowledgments The authors thank Piper Bittman and Elizabeth Georgio for their assistance with data collection and preparation of the intervention materials.

Funding This study was funded by the Organization of Autism Research (grant number 2019G06, PI, L. Glugatch). The first author received funding for her doctoral program through a U.S. Department of Education, Office of Special Education Programs, Leadership Preparation Grant awarded to the second author (Project HEART: Heightened Excellence in Autism Research and Training, award \#H325D150082, PI, W. Machalicek).

Availability of data and material Not applicable.Supplementary Information The online version contains supplementary material available at https://doi.org/10.1007/s43494-021-00043-5.

Code availability Not applicable.Supplementary Information The online version contains supplementary material available at https://doi.org/10.1007/s43494-021-00043-5.

\section{Declarations}

Conflicts of Interest The authors have no conflict of interest to report.

Ethics Approval All procedures performed were in accordance with the ethical standards of the institutional review board and with the 1964 Helsinki declaration.

Consent to Participate Informed consent was obtained from all individual participants included in the study.

\section{References}

Baker, M. J. (2000). Incorporating the thematic ritualistic behaviors of children with autism into games: Increasing social play interactions with siblings. Journal of Positive Behavior Interventions, 2(2), 66-84. https://doi.org/10.1177 /109830070000200201.

Banach, M., Iudice, J., Conway, L., \& Couse, L. J. (2010). Family support and empowerment: Post autism diagnosis support group for parents. Social Work with Groups, 33(1), 69-83.

Banda, D. R. (2015). Review of sibling interventions with children with autism. Education and Training in Autism \& Developmental Disabilities, 50, 303-315. https://doi. org/10.1007/s10803-014-2222-7.

Bank, S., \& Kahn, M. D. (1975). Sisterhood-brotherhood is powerful: Sibling sub-systems and family therapy. Family Process, 14(3), 311-337. https://doi.org/10.1111/j.15455300.1975.00311.x.

Barton, E. E., Meadan, H., \& Fettig, A. (2019). Comparisons of visual analysis, non-overlap methods, and effect sizes in the evaluation of parent implemented functional assessment 
based interventions. Research in Development Disabilities, 85, 31-41. https://doi.org/10.1016/j.ridd.2018.11.001.

Bene, K., \& Lapina, A. (2020). A meta-analysis of siblingmediated intervention for brothers and sisters who have autism spectrum disorder. Review Journal of Autism \& Developmental Disorders, 8, 186-194. https://doi. org/10.1007/s40489-020-00212-z.

Bontinck, C., Warreyn, P., Van der Paelt, S., Demurie, E., \& Roeyers, H. (2018). The early development of infant siblings of children with autism spectrum disorder: Characteristics of sibling interactions. PloS One, 13(3), e0193367. https://doi. org/10.1371/journal.pone.0193367.

Carr, J. E., Nicolson, A. C., \& Higbee, T. S. (2000). Evaluation of a brief multiple-stimulus preference assessment in a naturalistic context. Journal of Applied Behavior Analysis, 33(3), 353-357. https://doi.org/10.1901/jaba.2000.33-353.

Christopher, S., \& Shakila, C. (2013). Understanding siblings of children with autism. International Journal of Scientific Research, 2(10), 1-2. https://doi.org/10.15373/22778179 loct $2013 / 144$.

Cicirelli, V. G. (1994). Sibling relationships in cross-cultural perspective. Journal of Marriage \& the Family, 56, 7-20. https://doi.org/10.2307/352697.

Coelho, L., Torres, N., Fernandes, C., \& Santos, A. J. (2017). Quality of play, social acceptance and reciprocal friendship in preschool children. European Early Childhood Education Research Journal, 25(6), 812-823. https://doi.org/10.1080 /1350293x.2017.1380879.

Cohen, J. (1988). Statistical power analysis for the behavioral sciences (2nd ed.). Lawrence Erlbaum Associates.

Colletti, G., \& Harris, S. L. (1977). Behavior modification in the home: Siblings as behavior modifiers, parents as observers. Journal of Abnormal Child Psychology, 5(1), 21-30. https://doi.org/10.1007/bf00915757.

Ferraioli, S. J., Hansford, A., \& Harris, S. L. (2012). Benefits of including siblings in the treatment of autism spectrum disorders. Cognitive \& Behavioral Practice, 19, 413-422. https://doi.org/10.1016/j.cbpra.2010.05.005.

Gass, K., Jenkins, J., \& Dunn, J. (2007). Are sibling relationships protective? A longitudinal study. Journal of Child Psychology \& Psychiatry, 48(2), 167-175. https://doi. org/10.1111/j.1469-7610.2006.01699.x.

Giallo, R., \& Gavidia-Payne, S. (2006). Child, parent and family factors as predictors of adjustment for siblings of children with a disability. Journal of Intellectual Disability Research, 50, 937-948. https://doi.org/10.1111/j.13652788.2006.00928.x.

Gold, N. (1993). Depression and social adjustment in siblings of boys with autism. Journal of Autism Developmental Disorders, 23, 147-163. https://doi.org/10.1007 /bf01066424.

Hastings, R. P. (2003). Child behaviour problems and partner mental health as correlates of stress in mothers and fathers of children with autism. Journal of Intellectual Disability Research, 47(4-5), 231-237. https://doi.org/10.1046 j.1365-2788.2003.00485.x.

Hurwitz, S. C. (2002). To be successful: Let them play! Child Education, 79, 101-102.

Isenberg, J., \& Quisenberry, N. L. (1988). Play: A necessity for all children. Childhood Education, 64(3), 138-145.
Jarrold, C. (2003). A review of research into pretend play in autism. Autism, 7, 379-390. https://doi.org/10.1177 /1362361303007004004.

Kaminsky, L., \& Dewey, D. (2001). Siblings relationships of children with autism. Journal of Autism \& Developmental Disorders, 31, 399-410. https://doi.org/10.1023 /a:1010664603039.

Kazdin, A. E. (2011). Single-case research designs: Methods for clinical and applied settings. Oxford University Press.

Kramer, L. (2004). Experimental interventions in sibling relationships. In R. D. Conger, F. O. Lorenz, \& K. A. S. Wickrama (Eds.), Continuity and change in family relations. Lawrence Erlbaum Associates. https://doi.org/10.4324 /9781410609878-22.

Kratochwill, T. R., \& Levin, J. R. (Eds.). (2015). Single-case research design and analysis (psychology revivals): New directions for psychology and education. Routledge. https://doi.org/10.4324/9781315725994.

Kryzak, L. A., \& Jones, E. A. (2017). Sibling self-management: Programming for generalization to improve interactions between typically developing siblings and children with autism spectrum disorders. Developmental Neurorehabilitation, 20, 525-537. https://doi.org/10.1177/1744629514564450.

Kryzak, L. A., Cengher, M., Feeley, K. M., Fienup, D. M., \& Jones, E. A. (2015). A community support program for children with autism and their typically developing siblings: Initial investigation. Journal of Intellectual Disabilities, 19(2), 159-177. https://doi.org/10.1177 $/ 1744629514564450$.

Laghi, F., Lonigro, A., Pallini, S., Bechini, A., Gradilone, A., Marziano, G., \& Baiocco, R. (2018). Sibling relationships and family functioning in siblings of early adolescents, adolescents and young adults with autism spectrum disorder. Journal of Child \& Family Studies, 27, 793-801. https://doi.org/10.1007/s10826-017-0921-3.

Lin, C. E., \& Koegel, R. (2018). Treatment for higher-order restricted repetitive behaviors (H-RRB) in children with autism spectrum disorder. Journal of Autism \& Developmental Disorders, 48, 3831-3845. https://doi.org/10.1007/s10803018-3637-3.

Lobato, D. (1985). Brief report: Preschool siblings of handicapped children - Impact of peer support and training. Journal of Autism \& Developmental Disorders, 15(3), 345-350. https://doi.org/10.1007/bf01531505.

Lovell, B., \& Wetherell, M. A. (2016). The psychophysiological impact of childhood autism spectrum disorder on siblings. Research in Developmental Disabilities, 49-50, 226-234. https://doi.org/10.1016/j.ridd.2015.11.023.

MacDonald, R., Sacramone, S., Mansfield, R., Wiltz, K., \& Ahearn, W. H. (2009). Using video modeling to teach reciprocal pretend play to children with autism. Journal of Applied Behavior Analysis, 42(1), 43-55.

Macks, R. J., \& Reeve, R. E. (2007). The adjustment of nondisabled siblings of children with autism. Journal of Autism \& Developmental Disorders, 37, 1060-1067. https://doi. org/10.1007/s10803-006-0249-0.

McHale, S. M., Updegraff, K. A., \& Feinberg, M. E. (2016). Siblings of youth with autism spectrum disorders: Theoretical perspectives on sibling relationships and individual adjustment. Journal of Autism \& Developmental 
Disorders, 46(2), 589-602. https://doi.org/10.1007/s10803015-2611-6.

Oppenheim-Leaf, M. L., Leaf, J. B., Dozier, C., Sheldon, J. B., \& Sherman, J. A. (2012). Teaching typically developing children to promote social play with their siblings with autism. Research in Autism Spectrum Disorders, 6, 777-791. https://doi.org/10.1016/j.rasd.2011.10.010.

Orsmond, G. I., \& Fulford, D. (2018). Adult siblings who have a brother or sister with autism: Between-family and withinfamily variations in sibling relationships. Journal of Autism \& Developmental Disorders, 48, 4090-4102. https://doi. org/10.1007/s10803-018-3669-8.

Page, T. J., \& Iwata, B. A. (1986). Interobserver agreement. In: Research methods in applied behavior analysis (pp. 99-126). Springer. https://doi.org/10.1007/978-1-4684-8786-2_6

Parsons, M. B., Rollyson, J. H., \& Reid, D. H. (2012). Evidencebased staff training: A guide for practitioners. Behavior Analysis in Practice, 5(2), 2-11. https://doi.org/10.1007 /bf03391819.

Pustejovsky, J. E., \& Swan, D. M. (2018). SingleCaseES: A calculator for single-case effect sizes. $R$ Package Version $0.4,3$.

Reimers, T. M., \& Wacker, D. P. (1988). Parents' ratings of the acceptability of behavioral treatment recommendations made in an outpatient clinic: A preliminary analysis of the influence of treatment effectiveness. Behavioral Disorders, 14(1), 715. https://doi.org/10.1177/019874298801400104.

Rispoli, M., Camargo, S., Machalicek, W., Lang, R., \& Sigafoos, J. (2014). Functional communication training in the treatment of problem behavior maintained by access to rituals. Journal of Applied Behavior Analysis, 47(3), 580-593. https://doi. org/10.1002/jaba.130.

Roeyers, H., \& Mycke, K. (1995). Siblings of children with autism, with mental retardation and with a normal development. Child Care, Health \& Development, 2, 305-319. https://doi.org/10.1111/j.1365-2214.1995.tb00760.x.

Schopler, E., Van Bourgondien, M. E., Wellman, G. J., \& Love, S. R. (2010). Childhood autism rating scale (2nd ed.). Western Psychological Services.

Shivers, C. M., \& Plavnick, J. B. (2015). Sibling involvement in interventions for individuals with autism spectrum disorders:
A systematic review. Journal of Autism \& Developmental Disorders, 45, 685-696. https://doi.org/10.1007/s10803014-2222-7.

Simacek, J., Elmquist, M., Dimian, A. F., \& Reichle, J. (2020). Current trends in telehealth applications to deliver social communication interventions for young children with or at risk for autism spectrum disorder. Current Developmental Disorders Reports, 8(1), 1-9. https://doi.org/10.1007 /s40474-020-00214-w.

Smith, T., \& Perry, A. (2005). A sibling support group for brothers and sisters of children with autism. Journal on Developmental Disabilities, 11, 77-88.

Summers, M., Bridge, J., \& Summers, C. R. (1991). Sibling support groups. Teaching Exceptional Children, 23, 20-25. https://doi.org/10.1177/004005999102300405.

Tarlow, K. R. (2017). An improved rank correlation effect size statistic for single-case designs: Baseline corrected Tau. Behavior Modification, 41(4), 427-467.

Tsao, L. (2002). How much do we know about the importance of play in child development? Child Education, 78, 230-233. https://doi.org/10.1080/00094056.2002.10522188.

Tsao, L. L., Davenport, R., \& Schmiege, C. (2012). Supporting siblings of children with autism spectrum disorders. Early Childhood Education Journal, 40(1), 47-54. https://doi. org/10.1007/s10643-011-0488-3.

Tudor, M. E., \& Lerner, M. D. (2015). Intervention and support for siblings of youth with developmental disabilities: A systematic review. Clinical Child \& Family Psychology Review, 18(1), 1-23. https://doi.org/10.1007/s10567-014-0175-1.

Valentine, J. C., Tanner-Smith, E. E., Pustejovsky, J. E., \& Lau, T. S. (2016). Between-case standardized mean difference effect sizes for single-case designs: a primer and tutorial using the scdhlm web application. Campbell Systematic Reviews, 12(1), 1-31. https://doi.org/10.4073/cmdp.2016.1.

Ward-Horner, J., \& Sturmey, P. (2010). Component analyses using single-subject experimental designs: A review. Journal of Applied Behavior Analysis, 43(4), 685-704. https://doi.org/10.1901/jaba.2010.43-685.

Zoom Video Communications Inc. (2020). Security guide. Zoom Video Communications Inc. 